NBER WORKING PAPER SERIES

RECENT ESTIMATES OF TIME-VARIATION
IN THE CONDITIONAL VARIANCE AND
IN THE EXCHANGE RISK PREMIUM

Jeffrey A. Frankel

Working Paper No. 2367

NATIONAL BUREAU OF ECONOMIC RESEARCH

1050 Massachusetts Avenue

Cambridge, MA 02138

August 1987

The research reported here is part of the NBER's research program in International Studies. Any opinions expressed are those of the author and not those of the National Bureau of Economic Research. 
NBER Working Paper \#2367

August 1987

\section{Recent Estimates of Time-Variation in the Conditional Variance and in the Exchange Risk Premium}

\section{ABSTRACT}

The optimal-diversification model of investors' portfolio behavior can give a linear relationship between the exchange risk premium and the conditional exchange rate variance. This note surveys recent empirical work that allows for the conditional variance itself, and therefore the risk premium, to vary over time. In particular, it examines the implications of recent empirical estimates for earlier arguments, based on the assumption that the conditional variance was constant over time, that the exchange risk premium had to be small in magnitude and variability.

Jeffrey A. Franke1 Department of Economics University of California Berkeley, CA 94720 
Recent Estimates of Time-Variation in the Conditional Variance and in the Exchange Risk Premium

\author{
Jeffrey A. Franke1* \\ Department of Economics \\ University of California \\ Berkeley, CA 94720
}

August 12, 1987

\begin{abstract}
A variety of recent empirical evidence suggests that conditional variances of exchange rates vary over time. Examples based on observed second moments of exchange rates are Cumby and Obstfeld (1984), Hsieh (1984), Domowitz and Hakkio (1985), Diebold and Pauly (1986) and Diebold and Nerlove (1986). Lyons (1986) and Hsieh and Manas-Anton (1986) have extracted implicit variances from foreign exchange options data, and they confirm that investors' perceived variances vary over time.
\end{abstract}

The behavior of investors in the foreign exchange market depends on the conditional variance. In past work on the implications of mean-variance optimization by investors, I explicitly assumed that the conditional variances and covariances of returns were constant over time: "... [The] model employed here makes several simplifying assumptions... It assumes that the variance-covariance matrix is stationary... Each of these simplifications could, in theory, invalidate the results, and it would be desirable to relax each of them in future research." (1986, p. 260). From the first, I recognized

*The author would like to thank Francis Diebold, Charles Engel and Ken Froot for useful comments and discussion, and the Alfred Sloan Foundation and the Institute of International Studies at U.C. Berkeley for research support. 
that second moments can in fact change over time; but I argued that it was more important to begin by focussing on how first moments vary over time with asset quantities, such variation being crucial, for example, to the question of the effects of foreign exchange intervention.

It is certainly true that parameters such as the variances in our asset demand functions can change over time....But this paper is written under the supposition that fluctuations in expected returns are more of a problem than fluctuations in variances. After all, the former are the variables in the asset demand functions, and the latter are the parameters. Allowing expected returns to vary was first priority. Allowing the parameters to vary is a subject for future research. 1

The major thrust of these papers was that mean-variance optimization, because it implies a linear relationship between the exchange risk premium and the variance of the exchange rate, implies three propositions about the risk premium:

(1) it is small in absolute magnitude

(2) foreign exchange intervention or other changes in the supply of assets, has a small effect on it

(3) it does not vary much over time.

Several recent papers, largely inspired by the empirical findings that the conditional variance does indeed vary over time, explore what happens to arguments like mine regarding the magnitude of the risk premium when one relaxes the assumption that the variance is constant. This direction of research is a welcome acceptance of the invitation extended in the passages quoted above.

I. The upper bound on the conditional variance.

1 Franke1 (1985, 1062). The other relevant papers include Frankel (1982). 
Adrian Pagan challenges my use of the sample variance, as an upper bound on the conditional variance which investors use to think about risk, on page S63 of my 1986 JIMF paper. The variance for monthly changes in, for example, the pound/dollar rate around the forecasts of the forward rate is .010 on an annualized basis (page S56, col. (4) $\div 2$ ). Given a coefficient of relative risk aversion of 2 and the assumption that only the exchange rate is stochastic, mean-variance optimization can be seen to imply that the risk premium rp is given by $-V\left[\alpha+\frac{1}{2}\right]+2 V x$, where $V$ is the conditional variance, $\alpha$ is the share of foreign goods in consumption, and $x$ is the share of foreign assets in the portfolio. ${ }^{2}$ To simplify, assume that $\alpha$, which is in any case between 0 and 1 , is $\frac{1}{2}$. Then

$$
r p=-V+2 V x
$$

I used .010 as the upper bound for $V$. Thus my argument was that if the supply of marks is increased by one percent $(\Delta x=.01)$, then an upper bound on the change in the risk premium $\Delta \mathrm{rp}$ is .02 percent per annum, or 2 basis points. If the level of $x$ is close to 1 or 0 (even though it is unlikely that $x$ would in fact be that different from $\alpha$ ), then the magnitude of the risk premium could still be only as large as $V=1$ percent. See the earlier papers for the necessary assumptions, the derivation, and other citations.

Pagan gives an example of a statistical distribution that can have a conditional variance, for a particular realization in the preceding period, that is larger than the unconditional variance. The upshot of his comment is that

2 The expression gives the vector of risk premiums on $n$ assets if $\alpha$ is the vector of $n$ consumption shares, $x$ the vector of $n$ portfolio shares, and $\mathrm{V}$ the $\mathrm{n} \times \mathrm{n}$ variance-covariance matrix. 
I have not succeeded in putting an upper bound on the variance of the exchange rate and therefore I have not succeeded in putting an upper bound on the risk premium.

I would have thought uncontroversial my statement that the conditional variance "should be smaller than the unconditional variance," which is estimated by the sample variance. Let $\mathbf{e}_{t+1}$ be the change in the spot rate (in excess of the forward discount) in period $t+1, \operatorname{Var}(e)$ be the unconditional variance, $E_{t} e_{t+1}$ be the conditional expectation and $\varepsilon_{t+1}$ be the expectational error. Then

$$
\begin{aligned}
e_{t+1} & =E_{t} e_{t+1}+\varepsilon_{t+1} \\
\operatorname{Var}\left(e_{t+1}\right) & =E\left(e_{t+1}-E e_{t+1}\right)^{2} \\
& =E\left(\varepsilon_{t+1}+E_{t} e_{t+1}-E e_{t+1}\right)^{2}
\end{aligned}
$$

If we expand, use the fact that the conditional and unconditional expectations of $\varepsilon_{t+1}$ are zero and use $E\left(E_{t} e_{t+1}\right)=E e_{t+1}$, then we get

$$
\operatorname{Var}\left(e_{t+1}\right)=E\left(\varepsilon_{t+1}^{2}\right)+\operatorname{Var}\left(E_{t} e_{t+1}\right)
$$

The unconditional variance is equal to the variance of the expectational error plus the variance of the conditional expectation. If the conditional variance $V_{t} \equiv E_{t}\left(\varepsilon_{t+1}^{2}\right)$ is constant over time, then it is equal to $E\left(\varepsilon_{t+1}{ }^{2}\right)$, which from the equation above is clearly less than $\operatorname{Var}(e)$.

How then is Pagan's counterexample possible? His concocted distribution is in fact an instance of a much more fundamental (and obvious) point. If the 
conditional variance is at some times bigger than at other times, then the risk premiums will also be correspondingly bigger. A more transparent example than Pagan's is the case where the variance itself follows an autoregressive process, as in Robert Engle's (1982) ARCH model, so that a large squared realization in one period implies a large conditional variance in the following period. When I used the unconditional variance, estimated by the sample variance, as an upper bound on the conditional variance, I was thinking of both as constant over time, in which case my claims hold. If the conditional variance varies over time, then it is evident that my bound can be exceeded in those periods when it is especially large. Estimates in Engel and Rodrigues (1987), explained below, indeed show the conditional variance at times during the 1973-85 sample period substantially exceeding the bound of the unconditional variance (Figures $1 A-1 D)$

If we allow the conditional variance $v_{t}$ to vary over time, then one can still apply the upper bound to the average conditional variance, $E_{t} \equiv$ $E\left[E_{t}\left(\varepsilon_{t+1}^{2}\right)\right]=E\left(\varepsilon_{t+1}{ }^{2}\right)$, which appears in the above equation, and therefore to the average risk premium. If the conditional variance is 10 times larger than .010 one period in ten (for example, when the preceding squared realization was particularly large), then it is true that a one percent change in the portfolio in that period will change the risk premium by as much as 0.2 percent per annum, and that the magnitude of the risk premium could theoretically be as large as 10 percent per annum (if close to 100 percent of the portfolio is in one asset or the other). But in the other nine periods out of ten, these magnitudes would have to be zero for the variance to average out to .010 .

Thus the conclusion is that if we allow for the variance to vary over time, claims (1) and (2) above remain true if interpreted in the appropriate sense of averages over time. A consequence of allowing the variance to vary over 
time, however, is that variation in asset supplies $x$ is not the only source of variation in the risk premium $\mathrm{rp}$, so that claim (3) above is now suspect. This point is made by Giovannini and Jorion (1987a), to whom we now turn.

\section{Conditioning on the interest rate.}

To evaluate the implications for the variation of the risk premium, as in claim ( 3 ), we need to quantify somehow the variation of the conditional variance. The variation in daily or weekly squared exchange rate changes is very large. Giovannini and Jorion (1987a) report a variance of weekly squared changes equal to .001725 (a standard deviation of 4.2 per cent) for the mark/dollar rate, 1979-84 (p. 111). Even when squared daily changes are averaged within a month, the monthly variances still vary greatly. For 100 months from December 1977 to April 1986, the mark/dollar variances of daily changes appear to range from .00074 (a standard deviation of 2.72 per cent) in the most stable month to as large as .70619 (a standard deviation of 49.87 per

cent). (The source is Frankel and Meese (1987). $)^{3}$ The question is what fraction of the variation in these squared exchange rate changes could investors have foreseen based on available information.

3 These are the second moments computed around zero. We will in fact be interested in the second moment computed around the first moment. But there is wide agreement that only a very small proportion of exchange rate changes can be explained by either the forward discount, investor expectations, economists' models, or anything else. My argument, addressed by Pagan, that the sample variance can be taken as an upper bound is again relevant. 
Giovannini and Jorion (1987a) model the conditional variance by assuming a linear dependence on domestic and foreign interest rates. ${ }^{4}$ They obtain an $\mathrm{R}^{2}$ of .063 for squared weekly exchange rate changes, on mark/dollar data for 1979-84 (p. 111). The implication is that the variance of the predictable component of squared weekly exchange rate changes is $.063 \times .001725=1.1 \times 10^{-4}$ (not 1.1 as reported in their original paper).

It may be worth pausing to consider how Giovannini and Jorion (1987a) may have made their arithmetic mistake, because many others have made similar mistakes in this context. The danger, it seems, comes in from the beginning expressing exchange rate changes in per cent terms (e.g. 10) instead of absolute terms (.10). When standard deviations are squared to get variances $V$, a factor of $10^{4}$ is introduced (100 instead of .01). This seems perfectly harmless because the intent in the end is to use $V_{t}$ to match a risk premium or rate of return expressed in per cent per annum (say 3 instead of .03). But having squared in the meantime, we end up still off by a factor of $10^{2}$. (This is the way the mistake in expressing variances is usually made. Giovannini and Jorion were off by a factor of $10^{4}$, probably because they work with the variance of the variance.)

I propose a simple convention be followed in estimates of mean-variance optimization to avoid this problem in the future. Variances of exchange rate changes should be computed in absolute terms, e.g. .01. At the same time, the standard deviation can be parenthetically expressed in percentage terms (e.g. 10 per cent), so as to provide the necessary reasonableness-check for the author and the necessary intuition for the reader. Only after the implications for

4 Giovannini (1986) offers a theoretical justification for the relationship between the level of the interest rate and the time-varying volatility. 
the risk premium are worked out should the author multiply by $10^{2}$ if he wants it to be expressed in per cent, or $10^{4}$ to be expressed in basis points. If the variance is originally computed on shorter-term data than annually, say weekly data, on the common assumption that investors reshuffle their portfolios that often, then the effects on the risk premium will also be multiplied by 52 at the end, to convert the risk premium to a per annum basis. The weekly exchange rate changes should not be multiplied by 5,200 (to get returns in per cent per annum) before the variances are computed.

What variability of the risk premium is implied by Giovannini and Jorion's (corrected) estimate of the variance of the conditional variance? To state the strongest possible case for the risk premium, let us take the portfolio share $\mathrm{x}=1$. Then, equation (1) becomes

$$
r p_{t}=v_{t}
$$

the risk premium is given very simply by the conditional variance $V_{t}$. Thus the Giovannini-Jorion estimate implies that $1.1 \times 10^{-4}$ is also the variance of the risk premium on a per-week basis, which is a large standard deviation of 54.5 per cent $\left(.545=52 \times \sqrt{1.1 \times 10^{-4}}\right)$ on a per annum basis. ${ }^{5}$

5 The variance of the per annum risk premium is .297. Another way to get the same answer that is more in keeping with convention in finance is first to multiply the conditional variances at each point in time by 52 to express them in per annum terms. If investors are assumed to determine their portfolios once a year rather than once a week, this might be precisely the correct way to express the variances, on the theory that if the exchange rate process follows geometric Brownian motion in continuous time, then the variance grows linearly with the time interval. In any case, the estimate of the variance of the variances, and therefore the variance of the risk premium, comes out the same: larger ( $\operatorname{than} 1.1 \times 10^{-4}$ ) by $52 .^{2}$. 


\section{Conditioning on lagged volatility.}

A number of papers estimate the conditional variance time series by conditioning on lagged variability, as in the ARCH model of the variance, instead of on interest rates. Let this period's conditional variance depend linearly on last period's squared error:

$$
v_{t}=v_{0}+\rho \varepsilon_{t-1}^{2}
$$

Hsieh (1985) finds that after an innovation in the variance of the mark/dollar rate, the peak effect on the conditional variance occurs eight days later. ${ }^{6}$ Mark (1987) estimates a first-order ARCH process on monthly exchange rate data for four currencies; the estimate of $\rho$ for the mark/dollar rate is .240 (Table 2). Engel and Rodrigues (1987) estimate a first-order ARCH process on monthly data for five currencies; their largest estimate of $\rho$ for the mark/dollar rate is a somewhat smaller $.384^{2}=.148$ (Table 2). Allowing for longer ARCH lags tends to give an estimated variance process that dies out more slowly. Domowitz and Hakkio (1985), also working with monthly data, estimate a 4th-order ARCH process; the sum of the four (squared) lag coefficients for the mark/dollar rate is .521. Diebold and Nerlove (1986) estimate lags that go back almost as far, but on weekly data; the sum of the lags on their 12th-order ARCH process is .766 for the mark/dollar rate (Table 7). Given that some of the .766 effect on the

6 A unit innovation in $V_{t}$ is reported to have an effect of .225 on the conditional variance $\mathrm{V}_{t+8}$, and an effect .087 on $\mathrm{V}_{t+30}$. Similarly, Frankel and Meese (1987, Table 3) compute monthly correlations of daily variances for the mark/dollar rate; the autoregressive coefficient on the first month $\mathrm{lag}$ is .14 . But the effect of an innovation in $\varepsilon_{t}^{2}$, as specified in equation (3), should be greater than the effect of an equal innovation in $v_{t}$. 
first week's variance must die out by the fourth week, the estimate seems roughly in line with the Domowitz and Hakkio estimate.

We now derive the relationship between the (unconditional) variance of the conditional variance and the autoregressive parameter $\rho$ from the ARCH process (3). First we need an expression for the (unconditional) mean of the conditional variance. 7

$$
\begin{aligned}
V \equiv E V_{t} & =V_{0}+\rho E \varepsilon_{t-1}{ }^{2} \\
& =V_{0}+\rho V
\end{aligned}
$$

$$
V_{0}=V(1-p)
$$

We use equation (3) again in deriving an expression for the variance of the variance:

$$
\begin{aligned}
\operatorname{Var}\left(V_{t}\right) & =E\left(V_{t}^{2}\right)-\left(E V_{t}\right)^{2} \\
& =E\left(V_{0}+\rho \varepsilon_{t-1}{ }^{2}\right)^{2}-V^{2} \\
& =\left(V_{0}{ }^{2}+2 V_{0} \rho E \varepsilon_{t-1}{ }^{2}+\rho^{2} E \varepsilon_{t-1}{ }^{4}\right)-V^{2} \\
& =V_{0}{ }^{2}+2 V_{0} \rho V+-V^{2}+\rho^{2} E \varepsilon_{t-1}{ }^{4} \\
\text { Using (4), } & =V^{2}(1-\rho)^{2}+2 V^{2}(1-\rho) \rho-V^{2}+\rho^{2} E \varepsilon_{t-1}^{4}
\end{aligned}
$$

7 In what follows we use the assumption that the unconditional moments are constant over time, even though the conditional moments vary. 


$$
\begin{aligned}
& =V^{2}\left(1-2 p+p^{2}+2 p-2 p^{2}-1\right)+\rho^{2} E \varepsilon_{t-1}^{4} \\
& =p^{2}\left(E \varepsilon_{t-1}^{4}-V^{2}\right)
\end{aligned}
$$

We cannot eliminate the fourth-power term without additional information. But if we are willing to assume that the conditional distribution of $\varepsilon_{t-1}$ is normal (we already know that it has mean zero and variance $v_{t-1}$ ), then we can use a well-known property of the normal distribution: ${ }^{8}$

$$
E_{t-2^{\varepsilon} t-1}^{4}=3 E_{t-2^{\varepsilon} t-1}^{2}=3 V_{t-1}^{2}
$$

Thus

$$
\mathrm{E}_{\mathrm{t}-1}{ }^{4}=\mathrm{EE}_{\mathrm{t}-2^{2} \mathrm{t}-1}{ }^{4}=3 \mathrm{EV}_{\mathrm{t}-1}{ }^{2}
$$

We use (3) again $\quad=3 E\left[\left(\mathrm{~V}_{0}+\rho \varepsilon_{t-2}\right)^{2}\right]$

$$
\begin{aligned}
& =3\left[\mathrm{~V}_{0}^{2}+2 \mathrm{~V}_{0} \rho \mathrm{E} \varepsilon_{t-2}{ }^{2}+\rho^{2} \mathrm{E} \varepsilon_{t-2}{ }^{4}\right] \\
\mathrm{E} \varepsilon_{\mathrm{t}}^{4}\left(1-3 \rho^{2}\right) & =3 \mathrm{~V}_{0}\left(\mathrm{~V}_{0}+2 \rho \mathrm{V}\right)
\end{aligned}
$$

8 Engel and Rodrigues and the other ARCH estimates generally assume a conditional normal distribution anyway. Note that with a time-varying variance, the unconditional distribution will not be normal. (So $\mathrm{E} \varepsilon^{4} \neq 3 \mathrm{~V}^{2}$, for example.) A number of authors have suggested that the common finding of "fat tails" in the unconditional distribution could be explained as such a mixture of normals over time. Boothe and Glassman (1986, Table 3) find evidence that the daily distribution of the mark/dollar rate may switch back and forth between a normal with a standard deviation of .399 per cent and a normal with a standard deviation of 1.103 per cent. 


$$
=3 V(1-p) V(1+p)
$$

$$
E \varepsilon_{t}^{4}=3 V^{2}\left(1-p^{2}\right) /\left(1-3 p^{2}\right)
$$

Now we substitute (7) into (5)

$$
\begin{aligned}
\operatorname{Var}\left(V_{t}\right) & =p^{2}=\left(\frac{3 V^{2}\left(1-\rho^{2}\right)}{1-3 \rho^{2}}-v^{2}\right) \\
& =\rho^{2}=\left(\frac{3 v^{2}-3 v^{2} \rho^{2}-v^{2}+3 p^{2} v^{2}}{1-3 p^{2}}\right) \\
& =\rho^{2} 2 v^{2} /\left(1-3 p^{2}\right)
\end{aligned}
$$

The monthly sample variance of the forward rate prediction error is about $.001 .^{9}$ Even assuming that this is an accurate estimate of the unconditional variance of the forward rate prediction error, $\mathrm{Ee}_{t}{ }^{2}$, we must remember that it is only an upper bound on $\operatorname{Var}\left(\varepsilon_{t}{ }^{2}\right)=\mathrm{EV}_{t}$. We repeat equation (2) using $\mathrm{E}_{\mathrm{t}} \mathrm{e}_{\mathrm{t}+1}=r \mathrm{p}_{\mathrm{t}}$ :

$$
\operatorname{Var}\left(e_{t}\right)=E V_{t}+\operatorname{Var}\left(r p_{t}\right)
$$

9 Franke1 (1986). 
Even though the mean of $\varepsilon_{t}$ is zero under rational expectations, the mean of $\mathbf{e}_{t}$ is not zero unless the mean of the risk premium is zero (which is what we are trying to discover). The question is how much of the sample variance of $\mathrm{e}_{\mathrm{t}}(.001)$ is due to the variance of the risk premium and how much to the conditional variance.

We repeat our equation for the risk premium under mean-variance optimization and simple benchmark values for $x$ and risk-aversion:

(1') $\quad r p_{t}=v_{t}$

Equation (1') and our ARCH equation ( 8 ) give us

$$
\operatorname{Var}\left(r p_{t}\right)=\operatorname{Var}\left(V_{t}\right)
$$

$$
=2 p^{2} v^{2} /\left(1-3 p^{2}\right)
$$

On a monthly basis, if we take the Mark (1987) estimate of the ARCH parameter $p=.240$ and the estimate of the unconditional variance of the forward discount prediction error $\operatorname{Var}\left(\mathrm{e}_{t}\right)=.001$, it follows that the variance of the risk premium is on the order of

$$
\begin{aligned}
\operatorname{Var}\left(r p_{t}\right) & =2(.058)(.001)^{2} /(1-3(.058)) \\
& =.140 \times 10^{-6}
\end{aligned}
$$

and the standard deviation is $.374 \times 10^{-3}$, on a monthly basis. This implies that the standard deviation of the risk premium on a per annum bas is is .00449 
(0.45 per cent). The estimates in Diebold and Nerlove (1986) imply a strikingly similar annualized standard deviation of $52 \sqrt{.85788 \times 10^{-8}}=.0048 .^{10}$

The latest Engel-Rodrigues estimate $(p=.148)$ implies a somewhat smaller standard deviation. On the other hand, the standard deviation of the risk premium implied by the Giovannini and Jorion (1987b) estimate appears much larger.

\section{Variances extracted from options prices.}

\section{Estimates of implicit variances extracted from options prices are} potentially superior to the ARCH and other statistical methods in that they do not depend on any specific assumptions about what information investors use to forecast squared errors. ${ }^{11}$ Lyons (1986) reports annual variances for the log mark/dollar rate that vary over time over a range of approximately .01 to .04 (1983-1986), implying in our framework a risk premium that varies over a similar range. Hsieh and Manas-Anton (1986, Table 4) find that the estimated implicit volatilities differ considerably between put and call options and depending on the strike price and maturity of the contract. ${ }^{12}$ But the daily variance implicit in a typical call contract maturing in September 1984 showed

10 The calculation, reported to the author by Diebold, is based on the model on their p. 18, as estimated in Table 7. The time series for the conditional variance is graphed in Figure 3.

11

On the other hand, the Black-Scholes option-pricing formular was derived under the assumption that the variance is constant; its applicability to time-varying variances is not clear. Garman and Kohlhagen (1983) show how the Black-Scholes formula must be altered to be correctly applied to foreign currency options, in particular to allow for uncertainty in foreign interest rates in addition to domestic interest rates. 
a standard deviation across 81 price observations of .00094 . In our framework this implies a per day risk premium with a standard deviation on the order of .00094 . The standard deviation of the per annum risk premium is then .343, somewhat smaller than the Giovannini and Jorion estimate but still much larger than the ARCH estimates. It is a little disturbing that such different estimates of the variability of the conditional variance emerge, depending whether the variances are conditioned on the interest rate (Giovannini and Jorion), conditioned on lagged squared errors (Mark, Diebold and Nerlove, Engel and Rodrigues, and other ARCH estimates), or estimated from options prices.

\section{Can risk premiums derived from mean-variance optimization explain the behavior of the forward discount?}

How can we judge whether these numbers represent large or small variation in the risk premiums? A relevant standard of comparison for deciding what is "small" is the variation in the forward discount. Regressions of ex post spot rate changes against the forward discount commonly produce coefficient estimates closer to $1 / 2$ or 0 than to the unit value implied by the null hypothesis of forward rate unbiasedness. The many authors who assume that investors' expectations can be represented by ex post exchange rate changes in finite samples (up to a random error) thus infer that most, or even all, of the variation in the forward discount constitutes variation in the risk premium. See, for example, Fama (1984), Hodrick and Srivastava (1986), and Bilson (1985). (For elaboration, see and Froot and Frankel (1986).) The forward discount of the dollar against the mark has moved in the range 2 per cent per annum to 5

12 This tends to undermine the confidence one has in the option-price method of measuring the conditional variance. 
per cent per annum in recent years. The one-month forward discount had a standard deviation of 1.7 per cent per annum over the period January 1981-December 1986 (2.4 per cent over the period January 1974-December 1986). Thus some of the standard deviations of the conditional variances estimated above, do seem big enough potentially to explain the bias in the forward discount. ${ }^{13}$

Saying that movements in the variance are big enough to explain movements in the forward discount is not the same thing, however, as saying that these two variables do in fact move together, as they would need to if the risk premiums were to explain the forward discount's systematic prediction errors. Domowitz and Hakkio (1985) have used the ARCH estimates of the variance to try to explain the errors made by the forward discount in predicting spot rate changes, and Lyons (1986) has used the option-price estimates for the same purpose. Each has some (limited) success with some currencies. But one needs a hypothesis as to whether an increase in the variance should in theory raise the risk premium on the foreign currency or should raise the risk premium on the dollar. This requires some idea of what the supply of the foreign asset is relative to the minimum-variance portfolio. The asset whose supply exceeds

13

Giovannini and Jorion (1987b) come to the opposite conclusion once they correct their arithmetic error, that variation in the conditional variance is not big enough, afterall, to explain the behavior of the forward discount. But they use a smaller estimate of the share of the portfolio allocated to foreign currency, .1 rather than 1.0 , so the estimated variance of the risk premium is 100 times smaller than ours. An argument for a larger mark portfolio share such as .5 is that, even if marks are only $1 / 10$ of the world portfolio, dollars are far less than $9 / 10$ and the remainder is other currencies with which the mark/dollar rate is correlated. If $\mathrm{x}=\alpha=.5$ then the risk premium is zero regardless what the variance is (because the supply of marks is equal to the demand arising from the minimum-variance portfolio). We are using $x=1.0$ to state the strongest possible case for the risk premium. Indeed, the risk premium standard deviations that then come out of the Giovannini-Jorion or option-pricing estimates, with $\mathrm{x}=1.0$, appear too large to be plausible, rather than too small. 
the minimum-variance portfolio is the one that needs to pay a positive risk premium to be willingly held. Finding statistical evidence that the apparent effect of the variance is of the correct sign is more difficult than finding that it is non-zero.

Perhaps the most careful econometric study of mean-variance optimization across currencies that both uses asset supply data and allows for time-varying variances is Engel and Rodrigues (1987). Their use of the ARCH model of the variance-covariance matrix is to introduce it into the Maximum Likelihood technique from my 1982 paper, which imposes a constraint between the matrix of substitutability coefficients on the one hand, and the variance-covariance matrix of the error term in the same regression equation on the other hand. ${ }^{14}$ As in earlier papers, Engel and Rodrigues reject the hypothesis that the systematic prediction errors in the forward discount can be explained by mean-variance optimization. We are thus not yet at the point where we can claim to have found the risk variables that explain the behavior of the forward discount prediction errors.

14 In addition to using the ARCH model, i.e., conditioning the variance-covariance matrix on lagged squared errors, they also try conditioning on lagged squared innovations in the U.S. money supply and in oil prices. The conclusion regarding the hypothes is of mean-variance optimization is the same. 


\section{References}

Bilson, John. "Macroeconomic Stability and Flexible Exchange Rates." American Economic Review, May 1985, 79, 62-67.

Boothe, Paul and Debra Glassman. "The Statistical Distribution of Exchange Rates: Empirical Evidence and Economic Implications." University of British Columbia, 1986.

Cumby, Robert and Maurice Obstfeld. "International Interest Rate and Price Level Linkages Under Flexible Exchange Rates: A Review of Recent Evidence." In Exchange Rate Theory and Practice, edited by J. Bilson and R. Marston. Chicago: University of Chicago Press, 1984. Diebold, Francis and Marc Nerlove. "The Dynamics of Exchange Rate Volatility: A Multivariate Latent Factor ARCH Model." Special Studies Paper 205, Board of Governors of the Federal Reserve System, November 1986.

Diebold, Francis and Peter Pauly. "Endogenous Risk in a Portfolio-Balance Rational-Expectations Model of the Deutschemark-Dollar Rate." Board of Governors of the Federal Reserve System, September 1986.

Domowitz, Ian and Craig Hakkio. "Conditional Variance and the Risk Premium in the Foreign Exchange Market." Journal of International Economics, $1985,19,47-66$.

Engel, Charles and Anthony Rodrigues. "Tests of International CAPM with Time Varying Covariances." Unpublished mimeo, N.B.E.R., June 1987. Engle, Robert. "Autoregressive Conditional Heteroskedasticity with Estimates of the Variance of United Kingdom Inflation." Econometrica, 
50 (July 1982), 987-1007.

Fama, Eugene. "Forward and Spot Exchange Rates." Journal of Monetary Economics, $1984,14,319-338$.

Franke1, Jeffrey. "In Search of the Exchange Risk Premium: A Six-Currency Test Assuming Mean-Variance Optimization." Journal of International Money and Finance, December 1982, 1, 255-274. . "Portfolio Crowding Out, Empirically Estimated." Quarterly Journal of Economics, 1985, 100, 1041-1065.

- "The Implications of Mean-Variance Optimization for Four Questions in International Macroeconomics." Journal of International Money and Finance, March 1986, 5, S53-S75.

Franke1, Jeffrey and Richard Meese. "Are Exchange Rates Excessively Volatile?" NBER Working Paper, May 1987. Abridged in Macroeconomics Annual 1987, edited by S. Fischer.

Froot, Kenneth and Jeffrey Frankel. "Findings of Forward Discount Bias Interpreted in Light of Exchange Rate Survey Data." N.B.E.R. Working Paper No. 1963, June 1986. Revised, June 1987.

Garman, Mark and Steven Kohlhagen. "Foreign Currency Options Values." Journal of International Money and Finance," December 1983, 2, $3,231-237$.

Giovannini, Alberto. "Time-Varying Distributions of Returns, Nominal Interest Rates and Risk Premia in a Dynamic Asset Pricing Model." First Boston Working Paper no. 86-36, Columbia Business School, October 1986.

Giovannini, Alberto and Philippe Jorion. "Interest Rates and Risk Premia in the Stock Market and in the Foreign Exchange Market." Journal 
of International Money and Finance, March 1987, 6, 1, 107-124.

. "Foreign-Exchange Risk Premia Volatility Once Again." Columbia

University, 1987.

Hodrick, Robert and Sanjay Srivastava. "The Covariation of Risk Premiums and Expected Future Spot Exchange Rates." Journal of International Money and Finance, 1986, (Supplement): S5-22.

Hsieh, David. "Tests of Rational Expectations and No Risk Premium in Forward Exchange Markets." Journal of International Economics, 1984, $17,173-184$.

- "The Statistical Properties of Daily Foreign Exchange Rates: 1974-1983." University of Chicago, October 1985.

Hsieh, David and Luis Manas-Anton. "Empirical Regularities in the Deutsch Mark Futures Options." Center for Research in Security Prices, Working Paper No. 189. University of Chicago, 1986.

Lyons, Richard. "Tests of the Foreign Exchange Risk Premium Using the Expected Second Moments Implied by Options Pricing." M.I.T. mimeo, 1986.

Mark, Nelson. "On Time Varying Risk Premia in the Foreign Exchange Market." Journal of Monetary Economics, July 1985, 16, 3-18. . "Time Varying Betas and Risk Premia in the Pricing of Forward Foreign Exchange Contracts." Ohio State University, May 1987. Pagan, Adrian. "A Note on the Magnitude of Risk Premia." University of Rochester, October 1986. 